\title{
Paulo Freire y los cincuenta años de la Pedagogía del oprimido
}

\author{
Recibido: 01 septiembre $2020 \quad$ Aprobado: 30 Octubre 2020
}

Iván Nelson Angues Bambarén

Filiación: Universidad La Salle, RS-Brasil

Correo: anguesbambaren@gmail.com.

\section{Resumen}

El presente artículo trata de mostrar la faceta humana, de compromiso social y de principios de Paulo freire, uno de los más grandes pedagogos del siglo XX. De la misma forma, se elabora una breve síntesis de su principal obra: "Pedagogía del oprimido". Su pensamiento y obra, al igual que su metodología continúan vigentes. Sus ideas y método siguen siendo estudiadas y llevadas a la práctica en los cinco continentes. Es objetivo de este trabajo que se conozca más a este gran maestro de la pedagogía estudiado por muchos educadores y los más variados intelectuales del mundo. La mencionada obra ha sido traducida a más de una veintena de idiomas y es, sin lugar a duda, la más leída en el área de la educación. Igualmente, es también un modesto tributo al autor por los primeros cincuenta años de la publicación en español del libro aludido.

\section{Palabras clave:}

Paulo Freire, educación, pensamiento freireano, dialogicidad.

\section{Datos del autor}

Licenciado en Educación por la UNMSM, Lima -Perú; Diploma Internacional de formación de formadores en educación popular por la UARM, Lima-Perú; Magister en Lingüística Aplicada por la PUCRS, Porto Alegre-Brasil. Estudios completos de doctorado en Psicología Educativa por la UB, Barcelona-España. Profesor jubilado de la Universidad La Salle, RS-Brasil y profesor colaborador de la Organización no Gubernamental de Enseñanza Popular (ONGEP), Porto Alegre-Brasil. 


\section{Paulo Freire and the fiftieth anniversary of the Pedagogy of the oppressed}

\begin{abstract}
This article aims to show the human centered, social commitment and principles of Paulo Freire, one of the greatest pedagogues of the 2oth century. As also a brief synthesis of his main work: "Pedagogy of the oppressed." His work, as well as his methodology, are still valid. His ideas and method continue to be studied and put into practice on the five continents. It is the objective of this work that this great teacher of pedagogy, studied by many educators and the most varied intellectuals in the world, is better known. The aforementioned work has been translated into more than twenty languages and is, without a doubt, the most widely read in the area of education. Likewise, it is also a modest tribute to the author for fiftieth aniversary of the publication in Spanish of the previously mentioned book.
\end{abstract}

\section{Keywords}

Paulo Freire, education, freirean thought, dialogicity.

\section{Paulo Freire e os cinquenta anos da Pedagogia do Oprimido}

\section{Resumo}

O presente artigo trata de mostrar a faceta humana, de compromisso social e dos princípios de Paulo Freire, um dos maiores pedagogos do século XX. Da mesma forma, se elabora uma breve síntese de sua principal obra: "Pedagogia do oprimido". Seu pensamento e obra, tal como sua metodologia, continuam vigentes. Suas ideias e método seguem sendo estudadas e praticadas nos cinco continentes. É objetivo deste trabalho que se conheça mais este grande mestre da pedagogia estudado por muitos educadores e pelos mais variados intelectuais do mundo. A mencionada obra foi traduzida a mais de vinte idiomas e é, sem dúvida, a mais lida na área da educação. Igualmente, é também um modesto tributo ao autor pelos primeiros cinquenta anos da publicação em espanhol do livro aludido.
Palavras-chave:

Paulo Freire, educação, pensamento freireano, dialogicidade. 


\section{Una introducción y su contexto histórico ${ }^{1}$}

Es sabido la carencia y fragilidad que poseen los sectores menos favorecidos de la sociedad de tener acceso a los servicios más elementales para cubrir sus necesidades básicas tales como: vivienda, salud y educación. Esas carencias siguen vigentes en el Brasil actual y no es muy diferente en la inmensa mayoría de países latinoamericanos, pero vamos a detenernos concretamente al campo de la educación el interés de este artículo.

Hace más de 70 años, época en que el joven profesor Paulo Freire se iniciaba en la enseñanza, la situación del analfabetismo en Brasil, groso modo, era la siguiente: en los años 50 siendo Freire docente e investigador del Servicio social de la industria, SESI. Brasil contaba con 52000000 de habitantes y el $50 \%$ de la población brasileña era analfabeta. En el año de 1964 que marca la fecha de su prisión y exilio había una población 81000 ooo y el 39\% estaba conformado por analfabetos, aproximadamente (para datos más precisos ver Ferraro, 2006). En el noreste brasileño, área en donde se desempeñaba Paulo Freire, el analfabetismo, las dificultades y las desigualdades sociales eran mucho mayores. Esas privaciones y condiciones de vida del habitante brasileño fueron vivenciadas y marcaron hondamente en la sensibilidad del joven abogado y maestro e hicieron que ahondase sus estudios e investigaciones en el área de la educación, en especial, al inicio, en la alfabetización de adultos. Paulo Freire, ve en la educación la raíz, el sendero, el paso inicial a seguir para superar las inequidades de la sociedad brasileña.

A título de referencia, en el 2005 Brasil crea el programa: Brasil alfabetizado. "Entre 2005 y 2015 el número de analfabetos disminuyó cerca de 2 millones y medio lo que hace una media de 250000 por año. En ese ritmo para alfabetizar el total de 12900000 de analfabetos existentes serán necesarios cerca de 50 años" según nos lo dice, Braga y Mazzeu (2017 p. 44).

En esta biografía se intenta contextualizarlo con la época en que le tocó vivir, resaltando en la medida de lo posible, sus actitudes y convicciones que tuvo al momento de tomar decisiones y asumir responsabilidades. Las informaciones, relatos biográficos están basados en hechos relatados por el autor y el registro de su esposa, ambas plasmadas en las obras que se registran. Los comentarios que corroboran las afirmaciones freireanas son producto de mi experiencia profesional como profesor de la enseñanza secundaria desde el año198o, y de las vivencias a partir del año 2000 y hasta 2016 , como profesor universitario de las prácticas educativas de los alumnos de Letras de la universidad La Salle del Estado de Rio Grande do Sul en Brasil que me permitió observar a los profesores titulares y a los estudiantes, futuros profesores. De la misma forma, los últimos 8 años, paralelamente ejercí mi labor docente como profesor de secundaria en un colegio jesuita de la red privada de la ciudad de Porto alegre, RS-Brasil.

A continuación, se tratará su biografía, un análisis breve de su obra: “Pedagogía del oprimido" y finalmente las conclusiones sobre la vigencia y aplicación de su pensamiento en la educación actual.

1 Todas las traducciones de este artículo del portugués al español fueron hechas por mí. 


\section{Biografía de Paulo Freire: El hombre de la palabra y sus convicciones}

Se anhela en esta biografía presentar no solo los principales datos y actos realizados a lo largo de su vida, sino, además, resaltar algunas acciones que hacen honor al subtítulo de este relato de su vida. El subtítulo de esta biografía intenta mostrar una parte esencial de su personalidad, en especial su carácter. Se sabe que la palabra carácter deriva en el idioma griego de kharakter y en el latín de character, carácter: lo que graba, aquello que marca, el sello de cada persona. El diccionario de la Real academia española, (DRAE) así lo define: "conjunto de cualidades o circunstancias propias de una cosa, de una persona o de una colectividad, que las distingue, por su modo de ser u obrar, de los demás".

Freire, siempre fue fiel a sus convicciones y al hecho de cumplir su palabra, de respetar y honrar los compromisos asumidos. La expresión, la palabra, que aparece acompañando a este subtítulo de su biografía, lo podemos ver también, desde un punto de vista conceptual en su aspecto lato. Paulo Freire era un amante de su lengua materna, fue muchos años profesor de portugués, le gustaba colocar la palabra y el verbo adecuado, analizaba y examinaba el verbo, si este, por ejemplo, era transitivo o no, y la función que cumplía. Estos detalles pueden ser comprobados en la inmensa mayoría de sus textos, entrevistas y conferencias. Paulo, tenía el gusto y la dedicación de ser minucioso, como todo buen investigador, en el más mínimo detalle, quería que no quepa la menor duda de aquello a lo que se estaba refiriendo. Respecto a la enseñanza, afirmaba que esta exigía investigación, rigurosidad metódica y respeto a los saberes del educando. A estos temas el autor será perseverante (Freire, 2006 pp. 26-30).

Paulo Reglus Neves Freire, nace el 19 de septiembre de 1921 en la ciudad de Recife, Estado de Pernambuco. Trabaja en Brasil hasta el 1964, se exilia primero durante un mes en Bolivia hasta su llegada a Chile en noviembre de1964 en donde permaneció cinco años. Después vendrá su estancia y experiencia en los Estados Unidos, Europa, África, hasta su retorno definitivo al Brasil en 1986 y su fallecimiento en la ciudad de São Paulo en abril del 1997.

De sus primeros años de vida el autor recuerda con añoranza la vieja casa donde pasó su infancia: "relativamente grande, con un gran patio, rodeado de árboles, escuchando el canto de los pájaros, el viento, las tempestades, los truenos, al igual que los olores y colores de las flores, rosas y jazmines, las hojas, el árbol de mango y sus frutos, sus movimientos y sonidos, todo ello hizo de su imaginación llevarlo a lagos, islas, ríos y demás cosas que su mente imaginaba. De la misma forma, el recuerdo de los gatos, las gallinas y el perro negro de su padre, Joli". (Freire, 2005 pp.11-13). Las relaciones con sus hermanos y el universo del lenguaje de y con los más adultos, las expresiones, gustos, creencias de ellos son las reminiscencias de lo que Paulo Freire llamaba su mundo inmediato, su primer mundo, su universo. Esas experiencias lo enriquecerían y le serviría futuramente como fuente teórica de sus obras. Esas impresiones de vida cimentarán las bases de lo que más tarde será su creativa pedagógica y, seguramente, haya servido en la creación de una de las citas más emblemáticas del autor: “ $A$ leitura do mundo precede a leitura da palavra" (Freire, 2005 p.11).

Grandes vivencias marcan su niñez, es en esa realidad y en ese contexto que inicia su proceso de alfabetización: "Fui alfabetizado en el suelo del patio de mi casa, bajo la sombra de los árboles de mango, con palabras de mi mundo y no del mundo mayor de mis padres. El suelo fue mi primera pizarra, las pequeñas ramas, mi tiza" (Freire, 2005 p. 15). 
El pequeño Paulo, prestaba atención a los diálogos de los mayores, veía el firmamento, el sol, las estrellas, los árboles, escuchaba la lluvia, observaba y jugaba con todo aquello que la naturaleza le proporcionaba, y comenzaba a rasguñar en el suelo con las ramas sus primeras impresiones en ese su mundo inmediato. Así, iba alfabetizándose, amalgamando el texto con el contexto y con la ayuda y mirada atenta de sus padres. Su primera maestra fue Eunice, él tenía seis años y con ella aprende a amar el idioma. Paulo, siempre reconoció esa fase de su vida y mantuvo siempre la gratitud por su primera maestra. Hay un pasaje que transcribe su esposa de una entrevista aparecida en la revista Nova Escola No 81, diciembre de 1994: "Cuando Eunice me enseñó, era una chica de 16 o 17 años. Sin que yo, todavía me diera cuenta, me hizo percibir la primera llamarada con relación a una indiscutible amorosidad, que tengo hoy y desde hace mucho tiempo, por los problemas del lenguaje y particularmente del lenguaje brasileño... Paulo, repara bien como es bonita la manera que la gente ¡tiene de hablar!” (Freire, 2017 p.52).

Vive en la ciudad de Recife hasta los 10 años, era el año de 1932. La debacle de la bolsa de New York del 1929 desata la gran crisis mundial que perdura por varios años, afecta también al resto del mundo. Estados Unidos era el principal importador del café brasileño. La familia de Paulo Freire, como tantas familias de clase media que empobrecieron, se ve también afectada y se traslada a vivir a la ciudad de Jobatão a $18 \mathrm{~km}$ de la ciudad de Recife, años más tarde en el 1934, a los 13 años pierde a su padre, el sostén de la familia.

Corría el año de 1937 y Paulo Freire, consigue estudiar becado en el colegio Oswaldo Cruz de Recife en donde cursa los últimos años de la secundaria y años después, en la misma institución, dadas sus cualidades y al apoyo del Dr. Aluízio Pessoa de Araújo, director del emblemático colegio Oswaldo Cruz de Recife, Paulo se tornará profesor de portugués por varios años (trabajará también en otras instituciones educativas de Recife) y allí conocerá y tendrá una tierna amistad con Ana Maria Araújo, hija del director y dueño del colegio. Las circunstancias hicieron que esa persona se convirtiera décadas después en la segunda esposa de Paulo Freire, después de haber perdido ambos a sus respectivos cónyuges.

Inicia en 1943 sus estudios en la Facultad de Derecho, profesión que ejercerá por cortísimo tiempo. En 1944 se casará con la profesora Elsa Maria Costa de Oliveira con quien tuvo 5 hijos, fue su compañera y gran colaboradora hasta su partida el 24 de octubre del 1986. En 1947 todavía como profesor de portugués en el colegio Oswaldo Cruz, recibe la invitación del recién creado departamento del Servicio Social de la Industria, SESI. Creado con la finalidad de promover el bienestar social, cultural y mejoría de la calidad de vida del trabajador de las industrias y que cuenta con el soporte económico de la Confederación Nacional de la Industria. Paulo Freire acepta este trabajo, y a pesar de las discrepancias que podía tener con la persona e institución que lo contratan, a Paulo Freire le seduce el cargo e ingresa a trabajar al área de proyectos en el campo de la asistencia social y así comienza una nueva aventura pedagógica.

La década del 50 fueron años intensos de trabajo como docente e investigador. Su trabajo en el SESI en la sección Educación y Cultura lo llevó a viajar por muchos lugares de Brasil. Crea en el 1955 el Instituto Capibaribe con la intención de crear una escuela de enseñanza primaria y énfasis en la formación docentes y diversos cursos para la comunidad. Realiza con la Acción católica de Recife a mediados de los 50, una acción en beneficio de las camadas populares en los alrededores de la Parroquia del Arraial. En 1956, es considerado por el alcalde de Recife como uno de los más notables educadores de Pernambuco. Fue profesor de la hoy llamada Universidad Federal de Pernambuco, en la Escuela de Bellas Artes, fue nominado catedrático de la disciplina, Historia y Filosofía de la Educación. En el año de 1959 presenta su tesis doctoral para obtener su efectivización en la Escuela de Bellas Artes, intitulado: “Educación y actualidad brasileña". 
En 1960 en Recife con un grupo de profesores, artistas y otros intelectuales, alrededor de 100 personas, funda el Movimiento Cultural Popular (MCP). Un trabajo que desarrolla una gran e intensa actividad cultural en la ciudad, Freire era el responsable del sector educación. En el MCP, Freire plasma la idea de la alfabetización de adultos y pone en práctica su método en 1963 por la primera vez masivamente en la ciudad de Angicos, pequeño pueblo en el interior del Estado de Rio Grande do Norte con la colaboración financiera de la Agencia Internacional de Desarrollo de los Estados Unidos (AID) y el apoyo político y económico del Estado y del gobierno brasileño. Dado su éxito se crea en enero de ese año el Programa Nacional de Alfabetización de Adultos.

En abril del 1964, el golpe de Estado en Brasil (Latinoamérica vivirá hasta inicios de los 90 con muchas dictaduras militares) trae como consecuencia la cancelación del recién creado Programa Nacional de Alfabetización de Adultos, la prisión por 75 días de su coordinador, Paulo Freire, y el inicio de su largo exilio. En octubre de ese año se exilia primero en Bolivia, pero su estado de salud y el golpe de Estado al gobierno de Paz Estensoro inviabilizaron su permanencia en el país andino, el 20 de noviembre de 1964 llega a Chile para trabajar con el equipo del presidente demócrata cristiano Eduardo Frei en el Instituto de desarrollo Agropecuario hasta noviembre de 1967, desarrollando su trabajo en el sector de educación popular.

En la introducción de Pedagogía del oprimido, “primeras palabras”, queda la constancia que en diciembre de 1967 el profesor Ernani Maria Fiore, le entrega la famosa introducción: Aprender a dizer a sua palabra. Citado prólogo que el gran pedagogo siempre lo reconoció como un extraordinario resumen de su libro. Freire, termina la obra en el otoño del siguiente año y después de superar inconvenientes aparecerá por primera vez publicada en los Estados Unidos en el 1970. No fue su obra primigenia, antes había publicado Educação como prática da liberdade, pero sí, es la obra cumbre en la que Freire imprime los conceptos fundamentales para entender su propuesta y pensamiento filosófico.

Paulo Freire se desempeña después como consultor especial de Unesco en el Instituto de Capacitación e Investigación en Reforma Agraria hasta abril de 1969, en ese mismo mes y año, deja Chile y acepta el cargo de profesor convidado del centro de Estudios Sociales de la universidad de Harvard. Al año siguiente decide dejar de enseñar en Harvard, pues asume el compromiso, previamente acordado, de trabajar con el Consejo Mundial de las iglesias en Ginebra como consultor especial del departamento de Educación en donde se queda hasta el 15 de junio de 1980. Trabajó en muchos proyectos: fundación del Instituto de Acción Cultural dedicado fundamentalmente a la investigación, la universidad de Ginebra, proyecto con obreros italianos adultos, así como en Guinea, Cabo Verde, Angola y otros países africanos. Freire, no estuvo como asilado del gobierno suizo, y el 15 de junio al cumplir su compromiso en Suiza, decide regresar a Brasil.

Los últimos diecisiete años de Freire, fueron muy intensos. A los dos meses de regresar al Brasil, el dieciséis de junio de 1980 - antes estuvo solo 31 días a partir del siete de agosto de 1979 preparando su regreso, y en cuyo espacio, participa en la fundación del Partido de los trabajadores -, empieza a trabajar en el Programa de Posgraduación de la Pontificia Universidad Católica de São Paulo, (PUCSP) hasta la fecha en que fallece el dos de mayo de 1997. Freire, no hacía más que cumplir su promesa antes ofrecida al Arzobispado de São Paulo y Gran canciller de la universidad, Don Paulo Evaristo Arns, de ejercer la docencia a su regreso definitivo en la PUCSP. Paralelamente, y durante unos años también, fue docente en la Universidad Estadual de Campinas y en la medida que su tiempo lo disponía, no dejaba de colaborar con otras universidades, municipios e instituciones que solicitaban su presencia en diversos cursos, congresos y eventos educativos y culturales. 
Paulo Freire, se casa en 1987 con Ana Maria Araújo, aquella niña que había conocido, mientras él, joven adolescente estudiaba la secundaria en el colegio Oswaldo Cruz y en donde comenzó su trabajó como profesor de portugués. Es en esa misma institución en donde forjara sus primeros pasos que lo llevarían a ser más tarde el gran pedagogo universal en que se convirtió. En noviembre de 1988 acepta ser Secretario de Educación en el gobierno municipal de Luiza Erundina de Souza de la ciudad de São Paulo (1989-1992), función que ejerce hasta el veintisiete de mayo de 1991.

Se caracterizó su obra como Secretario de Educación por: reformular el currículo adecuándolo a los niños de las clases populares, revalorizar al personal docente, auxiliar y trabajadores de las escuelas. De la misma forma, hace partícipe a todos los integrantes de la comunidad educativa en las propuestas de las escuelas.

Cuatro directrices fueron los ejes de su gobierno: derecho de acceso a la escuela, la gestión democrática, la calidad de la enseñanza y la alfabetización de jóvenes y adultos. Pero también, por esos años sufre el ataque de un sector de la prensa paulistana por no concordar con la participación y el empoderamiento que Freire daba a la comunidad educativa al incluirlas en la sociedad. Como destaca Ana Maria Freire: “Del 1 de enero de 1989 al 27 de mayo de 1991, Paulo se dedicó exclusivamente de 'cambiar la cara de la escuela'. Para organizar una escuela pública de calidad, popular y democrática. A pesar de eso, de todo el esfuerzo y suceso que Paulo obtuvo con su trabajo en la Secretaría Municipal de Educación (...) o lo atacan profesionalmente y/o en sus posturas personales" (Freire, 2017 p.260).

La renuncia a la Secretaría Municipal de Educación se debió al deseo de Freire de continuar investigando y escribiendo, pasar más tiempo en casa con su esposa, Nita Freire. Necesitaba sosegar en algo, evitar más trajines de lo acostumbrado a su ya gastado estado físico. Desde la fecha que se aparta como secretario de Educación de São Paulo y a escasos meses de cumplir los 70 años, el fecundo trabajo se hizo muy presente, publica 7 libros y dejó muchos escritos por organizar. Paulo Freire, deja de existir físicamente en la ciudad de São Paulo el 2 de mayo de 1997. Paulo Freire, tuvo el reconocimiento hasta su fallecimiento de 41 títulos de Doctor Honoris Causa brasileñas y del exterior y posteriormente muchos otros más, Diversidad de títulos honoríficos, reconocimientos, homenajes, premios de la Unesco, OEA, y de varios países, escuelas, centros de enseñanza superior, Centros de Académicos, teatros, calles, auditorios, bibliotecas, revistas, canal de televisión, asociaciones comunitarias, Banco Comunitario, Cátedras, centros de Investigación, monumentos, presidente honorario de diversas instituciones, medallas, condecoraciones y premios que llevan su nombre en el Brasil y el mundo y otras más, como letras de música, etc. (ver todos los detalles en: Freire, 2017 pp. 441-458).

Hasta aquí una breve y justificable semblanza de la dilatada vida de Paulo Freire, que nos permite conocer a grandes rasgos parte de su vida y conocer momentos que muestran y reflejan su carácter y la personalidad de un hombre que se dedicó con ahínco a estudiar, trabajar, investigar, publicar, exponer sus ideas en variadas charlas y conferencias magistrales en los cinco continentes. Su objetivo fue luchar siempre por una educación, más justa, solidaria, una pedagogía humanizadora que liberte a los oprimidos de su opresión y que, como consecuencia, también, libertará a sus opresores.

\section{Sobre la "Pedagogía del oprimido"}

La obra de Paulo Freire está dividida en cuatro capítulos y de una introducción de obligatoria lectura hecha por el profesor Ernani Maria Fiori: “Aprender a dizer a sua palavra”. El propio 
Paulo Freire en muchas oportunidades valoró la magnífica síntesis e interpretación de su libro hecha en la introducción citada.

En el primer capítulo se sienta los principios básicos en que se fundamenta su obra, insiste en definir, aclarar algunas definiciones y sus respectivos opuestos, conceptos estos que considera esenciales para la comprensión de su trabajo. La humanización en oposición a la deshumanización en que vive el oprimido. La existencia del oprimido, porque hay un opresor. De otro lado, el oprimido ha de emprender una lucha por su humanización, pues existe una deshumanización, una inequidad. Deberá luchar por un trabajo con libertad y una desalienación, así el oprimido ganará su libertad, y como consecuencia, se libertará el opresor. “La libertad que es una conquista, y no una donación, exige una permanente búsqueda. Búsqueda permanente que solo existe en el acto responsable de quien la hace. Nadie tiene libertad para ser libre, por el contrario, lucha precisamente porque no la tiene" (Freire, 1978 p.35).

Freire, hace hincapié en no separar la objetividad de la subjetividad, no existe una sin la otra, pero llama a no confundir subjetividad con subjetivismo. Igualmente, hace la diferencia entre la generosidad auténtica, que es humanista y no "humanitarista”. “(...) la pedagogía que, partiendo de los intereses egoístas de los opresores, egoísmo camuflado de falsa generosidad, hace de los oprimidos objetos de su humanitarismo, mantiene y encarna la propia opresión. Es un instrumento de deshumanización" (Freire, 1978 p. 43). Otro de los tantos términos que analiza Freire, son los verbos ser y tener. El ser más es la aspiración del oprimido, en cambio, el tener más es propio del opresor.

Durante este primer capítulo y los siguientes Freire, declara y expone sus ideas, justifica, analiza dialécticamente la sociedad brasileña y chilena de esos tiempos, toma posición respecto a la conciencia y al mundo, parafraseando al profesor Ernani, no solo sincrónicamente, sino en diacronía con la historia. De otro lado, el autor nos lo recuerda: “Las páginas que siguen y que proponemos como una introducción a la Pedagogía del Oprimido son resultado de nuestras observaciones de estos cinco años de exilio. Observaciones que se vienen juntando a las que hicimos en Brasil, en los varios sectores en que tuvimos la oportunidad de ejercer actividades educativas" (Freire, 1978 p.19). Se puede añadir que los resultados de las investigaciones de Freire no son diferentes en su esencia a las demás sociedades latinoamericanas y del mundo, pues en todas ellas prima, incluso en los tiempos actuales, una educación en donde resalta la transferencia del conocimiento en detrimento de una educación más desafiadora, más crítica y menos estática, de eso intentaremos referirnos en el siguiente capítulo.

En el segundo capítulo el foco está en las relaciones que se dan entre la educación bancaria versus la educación transformadora, problematizadora en la definición de Freire, la superación de la contradicción educador/educando, en donde el profesor es el narrador, el agente activo, y el alumno el objeto paciente, oyente. Finalmente, terminará con la afirmación de la inconclusión del ser. El ser humano es inacabado.

Para Freire es fundamental estudiar y analizar las relaciones entre profesor y alumno, pues sabiendo identificarlos puede reconocer en el profesor el todo poderoso agente de la educación, y el alumno aquel que recibe las cantidades de contenidos que el sistema tiene preparado para él. La educación es un monólogo, prácticamente disertador, unidireccional. El educador se cree capaz que es el único que sabe y sus estudiantes serán los que no saben. Esta concepción de enseñar es la que el autor la denomina educación bancaria. Al alumno se le deposita conocimientos, se le transfiere conocimientos y valores, difícilmente se verifican los acontecimientos enseñados, se vive lo que Paulo Freire denomina una "cultura del silencio". 
En definitiva, el profesor será el sujeto del proceso enseñanza/aprendizaje y el estudiante un simple objeto. Quien escribe ha sido profesor en las dos ultimas décadas del siglo pasado profesor en la educación primaria y secundaria y en los últimos años he alternado mi función en la educación secundaria y universitaria, en ambas modalidades, en esencia la educación se caracteriza por ser bancaria, incluso aprovechándose hoy en día de las modernas herramientas tecnológicas educativas. Hay la excepción de algunos colegas y excepcionales escuelas, generalmente privadas, muy caras, dígase de paso, que hacen la excepción a la regla.

Una escuela en la que no intervienen activamente los padres o responsables de los alumnos y los propios estudiantes en la elaboración y discusión de la programación y de los contenidos programáticos, no deja de ser una escuela que practica una educación de corte bancaria, en oposición a una educación participativa, colaboradora, libertadora, que problematice la educación con la finalidad de contribuir a forjar un educando más crítico, libre y democrático y sea partícipe de los cambios por una sociedad más humana y comprometida con el entorno en el que vive. Paulo Freire, cree que un educador humanista y revolucionario al educar al educando él también se educa, y así, se humanizan ambos. La educación es un camino de doble vía. “(...) nadie educa a nadie, como que nadie se educa así mismo: los hombres se educan en comunión, mediatizados por el mundo" (Freire,1978 p.79).

La educación bancaria inhibe y niega la dialogicidad, elemento fundamental e insustituible en una educación libre y democrática, este tema será abordado en el siguiente capítulo.

El capítulo tercero se caracteriza por la dialogicidad, esencia de la educación como práctica de la libertad. Así textualmente Paulo Freire describe este capítulo. El autor considera la dialogicidad como la esencia del diálogo. Según el DRAE, el diálogo es la plática entre dos personas o más, que alternativamente manifiestan sus ideas o afectos. Paulo, creía en la fuerza de la palabra, pero que esta sea producto de una acción y una reflexión, y posteriormente la acción, no de una palabra hueca, sin praxis. Estaba convencido en el diálogo y que este debería ser sincero, simple y cordial, y que no se agotaba en la relación yo-tú. "No hay diálogo si no hay un profundo amor al mundo y a los hombres (...) siendo fundamento del diálogo, el amor es, también, diálogo" (Freire, 1979 pp. 93-4).

Hay una estrecha relación entre lo dialógico, lo problematizador y los contenidos programáticos educativos, no puede ser una imposición a los estudiantes, y menos aún, ser estos depósitos de dichos contenidos. El diálogo se inicia en la búsqueda del contenido programático. Parafraseando a Freire una educación real, auténtica, no se hace de A para B o de A sobre B, sino de A con B mediatizados por el mundo.

En este capítulo el autor desenvuelve también, el concepto del tema generador. Punto de partida que propaga e impulsa otros tópicos en la continuidad del proceso educativo. Es fundamental en la elaboración de contenidos programáticos para su aplicación en clase, es sin duda, consecuencia, producto de la dialogicidade. "No es una creación arbitraria o una hipótesis de trabajo que deba ser comprobada... es algo que llegamos a través no solo de la propia experiencia existencial, sino, también de una reflexión crítica sobre las relaciones hombre-mundo y hombres-hombres, implícitas en las primeras" (Freire, 1979 p. 103). Al igual que sabemos el dicho popular que la tierra genera la vida, "pois de uma maneira parecida as palabras geram pensamentos e geram conversas, são as "palavras geradoras". Brandão, C. (2005) p.55.

Finalmente, en el último capítulo se refiere a la antidialogicidade, opresión, dialogicidade, la liberación, y ser además, un resumen muy bien hilvanado de los tres capítulos anteriores. 
Freire, muestra su convicción democrática, su creencia y convicción en el diálogo como arma para combatir la opresión. No será revolucionario aquel que no es claro, que no practica el diálogo. Describe al revolucionario como aquel que tiene una visión humanista, concreta, no abstracta. Paulo Freire vive la época de las continuas dictaduras que acontecen en la gran mayoría de los países latinoamericanos, muchas de estas se autodenominaban revolucionarias, de ahí que insiste que un verdadero revolucionario apuesta al diálogo como exigencia revolucionaria, de lo que se desprende que revolución no podrá ser opresión. Del mismo modo, Freire deja entrever claramente que considera al docente que busca la liberación de sus estudiantes un revolucionario, desea de ellos, que tengan un pensamiento crítico del mundo y sean cada vez más humanos y solidarios, capaces de comprender su entorno social. "Críticos seremos, verdaderos, si vivimos a plenitud de la praxis" (Freire, 1979 p. 152).

No es el objetivo de este artículo profundizar en las características de la antidialogicidad y de su opuesto, la dialogicidad, estas merecen un espacio y estudio más exhaustivo, apenas vamos a dar unas breves peculiaridades de estas.

La antidialogicidad es conquistadora, dominadora, parte del concepto de dividir para dominar, es manipuladora, manipula a las personas, impone instrumentos para mantener esa dominación y no respeta la individualidad, condiciona una invasión cultural alienante. Las consecuencias son niños y niñas frustradas en su potencial, criadas en un ambiente de desamor, desvinculadas del docente, en donde prima la autoridad de la escuela, hay nulo o poco diálogo entre el educador y educando. Se vive un ambiente de miedo a la libertad.

La dialogicidad es colaboradora, no impone, no domina, no es manipuladora. El diálogo es la fuente de la comunicación, a diferencia de la antidialogicidad, el líder no es el propietario de las multitudes, es indispensable, pero no será dueño del pensar de los demás. Es una persona comprometida con la libertad del otro, y a su vez, también forma parte. No enfrasca ideas, las abre en grandes círculos de estudios, valga el oxímoron. La cultura del silencio de la antidialogicidad que generaba miedo, en esta oportunidad se abre. La dialogicidad es organización, es el camino a la libertad.

\section{Conclusiones}

Después de casi 30 años de la publicación de pedagogía del oprimido, el 2 de mayo de 1997 fallece el gran educador, para esa época Freire había escrito más de una decena de libros, innúmeras charlas, conferencias, en eventos dentro y fuera de Brasil. En la actualidad se cuentan por centenares los libros, artículos en revistas, homenajes de diversa índole que se realizan en su memoria.

Para la pedagoga e historiadora del gran educador, Ana Lúcia Freitas, "Freire se hace importante hoy, fundamentalmente, porque desacomoda y hace pensar, desafiándonos a recuperar la capacidad de soñar y movilizando la lucha colectiva en la defensa de las posibilidades de nuestros sueños" (Freitas, 2001 p.35)

El ideario de Paulo Freire va a corroborarse en diferentes países y continentes y se va desarrollando en las siguientes décadas con notable éxito, repitiendo así, la experiencia de 45 días de alfabetización con 300 trabajadores rurales aplicando el método de alfabetización freireano en la década del 60 en la ciudad de Angicos en el noreste brasileño. De ahí, la importancia de aproximarnos cada vez más, estudiar, analizar sus obras junto a su práctica educativa, pues 
nos facilitará la comprensión cabal de su pensamiento y, por lo tanto, de su aplicación y la puesta en práctica por la comunidad educativa con mayor asiduidad en las escuelas.

Finalmente, en una época actual que se habla tanto de empatía, tolerancia y respeto al otro, es de necesidad conocer la vida y estudiar las obras de este gran pedagogo brasileño, universal, humanista que luchó toda su vida por una escuela libre, democrática y laica, y que a pesar de ser un cristiano que nunca hizo apología ni manifestó de sus creencias de orden íntimo -salvo en su última entrevista 15 días antes de fallecer y ya delicado de salud, declara de forma breve y sin ningún afán proselitista su cristiano (Instituto Paulo Freire, 1997)-, su vida fue dedicada a luchar por darle a los desposeídos, al oprimido, el valor y lugar que merecen en la historia. Es en especial en su obra pedagogía del oprimido, en donde sienta las bases de su pensamiento y obra. Lecturas y estudios de sus obras contribuirán a no perder de vista el alcance, profundidad y objetivo del pensamiento freireano.

A modo de colofón, no se pretende con este breve trabajo agotar el estudio de la principal obra del autor, sino que es una invitación para otras relecturas y análisis y probables contribuciones que nos permitan reflexionar sobre un texto que no solo es fundamental y argumento clave para comprender y aplicar su ideario, sino saber que estamos ante una obra que transcurre y se retroalimenta en el tiempo, es actual, y la esencia de su pensamiento sigue vigente como fiel antorcha que guía a quienes creen que una educación crítica, problematizadora como le gustaba llamar Freire, es la base para una sociedad más justa, solidaria y equitativa.

Referencias bibliográficas

Braga, Ana Carolina \& Mazzeu, Francisco. (2017). O analfabetismo no Brasil. Revista en línea, $21(1), 24-46$.

Brandão, C.R. (2005) O menino que lia o mundo: Uma história de pessoas, de letras e de palabras. São Paulo. UNESP.

Real Academia Española. (2001). Diccionario. Madrid: Espasa.

Ferraro, A. 2006. Analfabetismo e níveis de letramento no Brasil. Educação e sociedade 23 (81), pp 21-47.

Freire, Ana Maria Araújo. (2017). Paulo Freire: Uma história de vida. ( $2^{\mathrm{a}}$ ed.) Rio de Janeiro/São Paulo: Paz e Terra.

Freire, P. (2005). A importância do ato de ler. São Paulo: Cortez.

Freire, P. (2006). Pedagogia da autonomia. São Paulo: Paz e terra.

Freire, P. (1979). Pedagogia do oprimido. Rio de Janeiro: Paz e Terra.

Freitas, Ana Lúcia Souza de. (2001). Pedagogia da conscientização. Porto Alegre: EDIPUCRS.

Instituto Paulo Freire (1997). La última entrevista de Paulo freire. https://freirepiaget.wordprees. com/freire/ 